\title{
MARGEN DE APRECIACIÓN NACIONAL, DIÁLOGO JUDICIAL Y ARGUMENTACIÓN RACIONAL: NOTAS DESDE LA EXPERIENCIA PERUANA*
}

\author{
NATIONAL MARGIN OF APPRECIATION, JUDICIAL DIALOGUE, \\ AND RATIONAL ARGUMENT: NOTES FROM \\ THE PERUVIAN EXPERIENCE
}

Pedro P. Grández Castro

Universidad Nacional Mayor de San Marcos, Perú

https:/ / orcid.org/0000-0001-7174-5534

\section{Resumen}

Este trabajo indaga sobre la presencia de la doctrina del margen de apreciación nacional (MAN) en el razonamiento desarrollado en el ámbito del sistema interamericano de derechos humanos. Aborda el tema desde una perspectiva de articulación entre la jurisdicción de la Corte IDH y las jurisdicciones de los Estados parte. El argumento que se defiende aquí se orienta a sostener que, en el marco de un proceso abierto de implementación de un modelo de constitucionalismo global de los derechos, un cierto MAN resulta no solo necesario, sino también indispensable para promover el diálogo judicial interamericano. Para lograr este objetivo, el trabajo se divide en tres partes: en la primera se realiza un breve recorrido por la doctrina del MAN y su justificación; en la segunda, se expone el debate desarrollado al respecto en el entorno del sistema interamericano; y en la última se presenta un ejemplo de lo que podría resumir un modelo de interacción racional dialogada a partir del caso peruano del control convencional del indulto a Alberto Fujimori.

* Texto desarrollado por el autor a partir de su ponencia presentada en el Congreso por los Cincuenta Años de la Convención Americana sobre Derechos Humanos, que se llevó a cabo en la Universidad Pompeu Fabra, los días 14 y 15 de noviembre de 2019. El autor agradece al profesor Alejandro Saiz Arnaiz de la Universidad Pompeu Fabra, de Barcelona, por haberle permitido publicar esta versión en el Perú. 
Palabras clave: margen de apreciación nacional, sistema interamericano de derechos humanos, diálogo judicial, argumentación convencional.

\begin{abstract}
The paper analyzes the presence of the national margin of appreciation doctrine (NMA) in the reasoning developed in the inter-American human rights system, from a perspective of articulation between the Inter-American Court jurisdiction and States internal jurisdictions. The argument that is defended in the paper maintains that, in the framework of an open process of implementation of a globalized model of constitutionalism, a certain level of NMA is not only necessary for the inter-American judicial dialogue, but also even indispensable. In order to achieve this objective, the work has three parts: the first presents a brief summary of the NMA doctrine and its justification; the second presents the debate developed in this regard in the inter-American system; and the last one shows an example of a rational interaction model based on the Peruvian case of conventional control of the amnesty received by President Alberto Fujimori.
\end{abstract}

Keywords: margin of national appreciation, inter-American human rights system, judicial dialogue, conventional reasoning.

\title{
1. Introducción
}

En abril del 2019, mediante una comunicación enviada al secretario ejecutivo de la Corte Interamericana de Derechos Humanos (Corte IDH), cinco países miembros del Pacto de San José le expresaron «las inquietudes de los Estados en relación con el actual funcionamiento del sistema regional de protección de derechos humanos». En la comunicación se sostiene que «los Estados gozan de un razonable margen de autonomía para resolver acerca de las formas más adecuadas de asegurar derechos y garantías», por lo que consideran que dicho margen «debe ser respetado por los órganos del sistema interamericano» ${ }^{1}$.

1 Ministerio de Relaciones Exteriores de Chile, Comunicado del 23 de abril de 2019. Disponible en: https://minrel.gob.cl/minrel/noticias-anteriores/comunicado-de-prensa-ministeriode-relaciones-exteriores-ministerio-de Ver también: Ministerio de Relaciones Exteriores de la República del Paraguay, Comunicado de Prensa del 24 de abril de 2019. Disponible en: 
La doctrina del «margen de apreciación», elaborada por el Tribunal Europeo de Derechos Humanos (TEDH) y desarrollada en medio de una constante controversia académica, ha ingresado en el ámbito interamericano como una reivindicación política por parte de algunos Estados con cierta orientación conservadora en la región. Quizá sea esta contaminación política lo que opaca, en alguna medida, la discusión académica, puesto que, con facilidad, las posturas parecen orientarse a negar su presencia y la posibilidad de su desarrollo $^{2}$, o, en algunos casos, a admitirla incurriendo en cierto realismo político antes que intentar justificar su necesidad en la dinámica de la argumentación racional propia de un tribunal jurisdiccional, como lo es la Corte $\mathrm{IDH}^{3}$.

En este sentido, el propósito de este trabajo es - luego de precisar el concepto de margen de apreciación en sus aspectos más relevantes - tratar de establecer un modelo de margen de apreciación nacional (MAN), necesario desde una perspectiva de la articulación entre la jurisdicción de la Corte IDH y las jurisdicciones de los Estados parte. Mi argumento en ese sentido, antes que ir en busca de alguna muestra descriptiva de la doctrina en el sistema interamericano, se orienta más bien a sostener que, en el marco de un proceso abierto de implementación de un modelo de constitucionalismo de los derechos globalizado (transconstitucionalismo), un cierto MAN resulta no solo necesario para el diálogo judicial interamericano, sino también indispensable. Si bien se trata de una tesis que por ahora no es necesariamente descriptiva sobre el modo de interacción entre la Corte IDH y las jurisdicciones de los Estados, hacia el final de mi trabajo mostraré un ejemplo que, desde mi punto de vista, resume bien un modelo de interacción racional dialogada a partir del caso peruano del control convencional del indulto a Alberto Fujimori.

https:/ / www.mre.gov.py /index.php/noticias-de-embajadas-y-consulados/gobiernos-deargentina-brasil-chile-colombia-y-paraguay-se-manifiestan-sobre-el-sistema-interamericanode-derechos-humanos

2 Claudio Nash Rojas, «La doctrina del margen de apreciación y su nula recepción en la jurisprudencia de la Corte Interamericana de Derechos Humanos», Anuario Colombiano de Derecho Internacional, ACDI 11, (2018), https://doi.org/10.12804/revistas.urosario.edu.co/ acdi/a.6539

3 Este parece ser el caso de Jorge Contesse, «Contestation and deference in the Inter-american Human Rights System», Law and Contemporary Problems 79, n 2 (2016): 123, https:// scholarship.law.duke.edu/lcp/vol79/iss2/6/ 


\section{Sobre la doctrina del margen de apreciación nacional (MAN)}

El MAN forma parte de los desarrollos jurisprudenciales del Tribunal Europeo de Derechos Humanos en su labor de control del poder de los Estado de la Unión. Su implementación y desarrollo, empero, no ha estado exento de debate y crítica. En el año 2013 fue incorporado mediante el Protocolo 15 como enmienda al Convenio Europeo de Derechos Humanos ${ }^{4}$, y entró en vigencia en agosto del $2021^{5}$, luego de ser ratificado por el número suficiente de Estados. Su presencia, aun en medio del debate, obedece al amplio consenso generado en Europa sobre el rol subsidiario que debe corresponder al TEDH en la protección de los derechos, la que corresponde siempre, en primer lugar, a cada uno de los Estados miembros del convenio. Entre las distintas formas de plantear su conceptualización, el MAN ha sido definido como un producto del principio de proporcionalidad ${ }^{6}$, un criterio de motivación ${ }^{7}$, una técnica de autocontención, una estrategia hermenéutica para la resolución supranacional de casos difíciles ${ }^{8}$, un criterio retórico de justificación ${ }^{9}$, una técnica de crea-

4 El Protocolo 15, aprobado por el Consejo de Europa en abril de 2013, incorpora la cláusula del margen de apreciación en los siguientes términos: Article 1.- At the end of the preamble to the Convention, a new recital shall be added, which shall read as follows: "Affirming that the High Contracting Parties, in accordance with the principle of subsidiarity, have the primary responsibility to secure the rights and freedoms defined in this Convention and the Protocols thereto, and that in doing so they enjoy a margin of appreciation, subject to the supervisory jurisdiction of the European Court of Human Rights established by this Convention".

5 Puede consultarse el texto íntegro en: https:/ / www.coe.int/en/web/conventions/full-list/-/ conventions/treaty/213

6 Javier García Roca, «La muy discrecional doctrina del margen de apreciación nacional según el Tribunal Europeo de Derechos Humanos: soberanía e integración», Teoría y Realidad Constitucional, n. ${ }^{\circ} 20$ (2007): 117-143, https: / /doi.org/10.5944/trc.20.2007.6778

7 Alfonso Herrera García, «Reseña de El margen de apreciación nacional en la interpretación del Convenio Europeo de Derechos Humanos: soberanía e integración de Javier García Roca», Revista Española de Derecho Constitucional 30, n. ${ }^{\circ} 90$ (septiembre-diciembre 2010): 393-397. https://dialnet.unirioja.es/servlet/articulo?codigo=7619529

8 Francisco R. Barbosa Delgado, «Los límites a la doctrina del margen nacional de apreciación en el Tribunal Europeo y la Corte Interamericana de Derechos Humanos: intervención judicial en torno a ciertos derechos de las minorías étnicas y culturales», Revista Derecho del Estado, n. ${ }^{\circ} 26$ (enero-junio 2011), https://revistas.uexternado.edu.co/index.php/derest/article/ view/2881

9 Javier García Roca, El margen de apreciación nacional en la interpretación del Convenio Europeo de Derechos Humanos: soberanía e integración (Cizur Menor, Navarra: Cuadernos Cívitas-Instituto de Derecho Parlamentario, Thomson Reuters, 2010). 
ción jurisprudencial ${ }^{10}$, y como un «mecanismo que hace posible la concreción del denominado principio de subsidiariedad $»^{11}$.

La falta de acuerdos en la definición del MAN puede deberse, en parte, al hecho de que la jurisprudencia emitida por el TEDH en aplicación de esta doctrina a lo largo de los años ha sido no solo polémica, sino también contradictoria. Como señala García, pese a los intentos que desde la teoría puedan hacerse para ordenar con mejor escrutinio las características de esta figura, la doctrina del MAN «produce una tremenda discrecionalidad de la Corte» al momento de su utilización ${ }^{12}$. Ello justamente ha llevado a que el mismo autor sostenga la posibilidad de estar frente a «un criterio de justificación en un sentido retórico, antes que [ante] un genuino método de interpretación de los derechos» ${ }^{13}$

No obstante, si bien esta situación dificulta su estricta caracterización, no hace imposible su clara distinción en comparación con otros conceptos cuyo vínculo con el MAN resulta clave para entender los alcances y límites de esta doctrina. Uno de dichos conceptos es el principio de proporcionalidad, respecto del cual es posible comprender con mayor claridad por qué el MAN es caracterizado como un criterio hermenéutico, interpretativo y argumentativo.

Desde esta perspectiva, al menos en su versión sustantiva, el MAN aparece como una deferencia hacia las autoridades nacionales respecto de cuestiones controversiales en las que la mirada local podría resultar no solo más legítima, sino también encontrarse «en mejor posición para determinar la necesidad y proporcionalidad de medidas que limiten los derechos del Convenio». En su versión procesal, sin embargo, el MAN sugiere un margen para el agotamiento de los recursos efectivos internos, siempre que estos resulten adecuados o, en todo caso, que las autoridades hayan actuado escrupulosamente ${ }^{14}$.

10 Pablo Sánchez-Molina, «Margen de apreciación nacional (en los sistemas de protección internacional de los derechos humanos)», Eunomía. Revista en Cultura de la Legalidad 9 (octubre 2015 - marzo 2016): 224-231, https://e-revistas.uc3m.es/index.php/EUNOM/ article/view/2823

11 José Ignacio Martínez Estay, «Autorrestricción, deferencia y margen de apreciación: breve análisis de sus orígenes y de su desarrollo», Estudios Constitucionales, 12, n. 1 (2014): 382, https:/ / scielo.conicyt.cl/scielo.php?script=sci_abstract\&pid=S0718-52002014000100009\&lng $=$ pt\&nrm $=$ iso

12 García Roca, «El margen de apreciación nacional...», 124, nota 6.

13 García Roca, «El margen de apreciación nacional...», 378, nota 9; García Roca, citado por Herrera, «Reseña...», 394, nota 7.

14 Luis María López Guerra, «El diálogo entre el Tribunal Europeo de Derechos Humanos y los tribunales españoles: coincidencias y divergencias», en Nuevas tendencias en la interpretación de 
Según Barbosa Delgado, «[t]anto en el sistema interamericano como en el europeo [el] principio de proporcionalidad se ha aplicado como punto de contacto entre el control judicial y el margen de apreciación nacional» ${ }^{15}$. Esto se debe a que, cuando una corte supranacional de derechos humanos efectúa un control sobre las actuaciones de los Estados, necesita valorarlas a través de un examen de razonabilidad basado en interpretaciones y contenidos de los derechos y principios reconocidos en los tratados. Sin embargo, en algunos casos, al momento de analizar los contextos específicos de cada Estado, los contenidos concretizados pueden enfrentar problemas relacionados con la complejidad interpretativa de los derechos humanos.

Esta complejidad interpretativa puede deberse, entre otras razones, a la dificultad de la corte para, en casos muy complejos, llegar a una comprensión cabal de la realidad social y cultural de una determinada sociedad; asimismo, puede estar relacionada (como ocurre con más evidencia en el ámbito europeo) a una falta de consenso entre las diferentes comunidades sobre una protección específica de determinados derechos fundamentales, o de algunas de sus dimensiones. En este tipo de casos, «[t]anto el TEDH como la Corte IDH, desde una perspectiva externa, se refieren al [MAN] como el espacio limitado de interpretación que tiene el Estado frente a los derechos fundamentales» ${ }^{16}$.

Es en este sentido que se entiende al MAN como un producto de la aplicación del principio de proporcionalidad. Y si se sigue a Robert Alexy, uno de los que mejor ha estudiado la proporcionalidad como estrategia de argumentación por parte de los tribunales, se tendría que precisar que el MAN es el resultado derivado de los llamados empates ponderativos, que son los que «fundamentan la existencia de [los] márgenes de acción estructurales» del principio de proporcionalidad ${ }^{17}$. Estos casos ocurrirían cuando el tribunal se enfrenta a una imposibilidad jurídica de dar una solución, puesto que, luego de aplicar los principios de idoneidad, necesidad y proporcionalidad en sentido estricto, se ha verificado que el tratado protege, con la misma intensidad, tanto las razones que avalan el derecho limitado por el Estado como aquellas que sustentan el principio que busca proteger el Estado con dicha limitación.

los derechos fundamentales, coord. José Vicente Gimeno Sendra y María Teresa Regueiro García (Madrid: Universitas, 2015), 21-44.

15 Barbosa Delgado, «Los límites a la doctrina del margen nacional de apreciación», 118, nota 8.

16 Barbosa Delgado, «Los límites a la doctrina del margen nacional de apreciación», 110.

17 Robert Alexy, «Epílogo a la Teoría de los Derechos Fundamentales», Revista Española de Derecho Constitucional 22, n. ${ }^{\circ} 66$ (septiembre-diciembre, 2002): 48. 
En todo caso — sin ingresar a dicho nivel de precisión conceptual—, desde esta primera perspectiva, puede decirse que:

[El MAN es considerado] un ingrediente más de[1] juicio de proporcionalidad; [es decir,] [u]n límite estructural a su aplicación que permite no entrar a revisar en ciertos casos la interferencia en el derecho si el fin de la restricción es legítimo, y la medida y la regulación son necesarias a ojos de las autoridades nacionales y todo ello no resulta irrazonable a la Corte ${ }^{18}$.

Así, el MAN funcionaría como una especie de «margen de acción estructural del legislador» ${ }^{19}$ para el caso del Estado, en respeto del «principio de deferencia al legislador democrático», lo cual, por supuesto, no significa que se está concediendo una deferencia a un espacio inmune de soberanía ${ }^{20}$.

Al respecto, hay que precisar, no obstante, que, en el caso del MAN, la existencia de dicho margen de acción estructural necesitará un nivel de justificación mucho más estricto, en la medida en que no nos hallamos en una situación en la que la corte supranacional solo se dirige al espacio de acción del legislador democrático, sino también, y especialmente, a la corte nacional de protección de derechos fundamentales. Esto se debe a que, dada la exigencia del principio de subsidiariedad, la corte nacional tendría que haberse pronunciado previamente sobre el caso.

De este modo, a diferencia de lo que ocurre en los casos donde una corte constitucional reenvía la decisión al legislador — con lo cual autorrestringe su competencia-, en el escenario del MAN la corte supranacional inicia un diálogo con la corte nacional en relación con la interpretación de un determinado derecho y su aplicación a un caso específico. El margen de acción supone, desde esta perspectiva, una interpretación cooperativa de los derechos protegidos por el convenio.

\subsection{Margen de apreciación y subsidiariedad}

Lo señalado en el apartado anterior nos lleva a otro concepto respecto del cual resulta necesario trazar límites a la hora de definir el MAN. Se trata del

18 García Roca, «El margen de apreciación nacional...», 121, nota 6.

19 Alexy, «Epílogo a la teoría de los derechos fundamentales», 48, nota 17.

20 García Roca, «El margen de apreciación nacional...», 114-115, nota 9, 202-204. 
principio de subsidiariedad. Según algunos autores, este principio no solamente constituye el fundamento del $\mathrm{MAN}^{21}$, sino que, además, es un «mecanismo que hace posible la concreción del principio de subsidiariedad $»^{22}$. Definiciones de este tipo, sin embargo, pueden generar, antes que claridad, una mayor confusión. Una forma mucho más rigurosa de vincular ambas nociones sostiene que el «principio de subsidiariedad [se] manifiesta en [el MAN] y es una de sus consecuencias, pero [sus] contenidos son más amplios» ${ }^{23}$.

La subsidiariedad puede ser mejor comprendida si se la asume como una forma de articulación entre dos órdenes de competencias: uno nacional y otro supranacional. En la dinámica entre sistema nacional e internacional, se crea una «cierta división de poderes» ${ }^{24}$ para la protección de algo que es compartido: los derechos humanos. De este modo, el MAN aparece como concreción de este reparto de poderes o de competencias, las cuales pueden considerarse positivas si se asume el MAN como una sesión de poder a favor de las responsabilidades nacionales para el cumplimiento del convenio; pero también negativas si se asume que el MAN supone un espacio de discrecionalidad para no imputar responsabilidad a un determinado Estado, una suerte de «regla de no decisión» ${ }^{25}$, un «perdón» por la omisión a favor del Estado, vistos sus esfuerzos o la diversidad de fórmulas para el cumplimiento del convenio.

García Roca se refiere a este extremo como «apariencia de buen derecho», es decir, un supuesto de justificación razonable que aconseja al tribunal internacional dejar el asunto en manos de las autoridades nacionales. Se enarbola, de esta manera, un «razonable principio de deferencia», sustentado en la «mejor posición del juez nacional para apreciar ciertos litigios frente a la torre de marfil europea ${ }^{26}$, que se proyecta siempre como un tribunal al que hay que acudir solo en forma subsidiaria.

En la medida que la subsidiariedad garantiza «la conjunción entre los niveles nacional e internacional», la primacía de la protección de los derechos debe concederse a los mecanismos internos de los Estados ${ }^{27}$. Por lo tanto, cuando la corte internacional decide reenviar el caso al Estado, su relación con

\footnotetext{
21 Martínez Estay, «Autorrestricción, deferencia y margen de apreciación», 379, nota 11.

22 Martínez Estay, «Autorrestricción, deferencia y margen de apreciación», 382.

23 García Roca, «El margen de apreciación nacional...», 121, nota 6.

24 García Roca, «El margen de apreciación nacional...», 99.

25 García Roca, «El margen de apreciación nacional...», 99.

26 García Roca, «El margen de apreciación nacional...», 115, nota 9.

27 García Roca, «El margen de apreciación nacional...», 122-123, nota 6.
} 
la corte nacional de dicho Estado puede ocurrir de dos formas. En la primera - a la que puede denominarse regular-, la corte internacional decide utilizar el MAN teniendo en cuenta las interpretaciones realizadas previamente por la corte nacional; y en la segunda - a la que se podría llamar excepcional-, la corte internacional opta por utilizar el MAN reenviando la decisión del Estado porque, si bien aún no se ha solucionado el caso en la vía nacional de manera previa e igualmente satisfactoria, la corte internacional estima necesario dar algunos alcances interpretativos sobre cómo debería resolverse el caso en el ámbito interno.

\subsection{Justificación del MAN}

Al margen del debate en torno a lo que define realmente al MAN —esto es, si se trata de: un poder discrecional o una forma de cooperación judicial interpretativa; una fórmula de deferencia a las autoridades nacionales; o incluso (a veces como se ha sostenido en tono crítico), una manera de «pasar por alto» alguna violación a los derechos por parte de las autoridades nacionales-, conviene detenerse en los argumentos que se han usado para justificar su presencia.

Así, aquel al que se puede denominar argumento estructural sugiere que el MAN solo expresa una cierta estructura en el reparto de las competencias entre el Estado y el sistema internacional de protección. De este modo, el sistema supraestatal se presenta como «complementario», o subsidiario a las falencias $\mathrm{u}$ omisiones de las autoridades nacionales. La formulación del Protocolo 15, que incorpora al MAN al preámbulo del Convenio, muestra con claridad esta dimensión estructural:

[L]as altas partes contratantes, de acuerdo con el principio de subsidiariedad tienen la responsabilidad primaria de asegurar los derechos y libertades definidos en este Convenio y sus protocolos, y al hacerlo así disponen de un margen de apreciación sujeto a la supervisión del Tribunal establecido por este Convenio ${ }^{28}$.

Considero que en esta línea de preocupaciones se encuentra también la propuesta de Marisa Iglesias, quien se refiere a un modelo normativo institu-

28 López Guerra, «El diálogo entre el Tribunal Europeo de Derechos Humanos y los tribunales españoles», nota 14. 
cional de subsidiariedad cooperativa. Según sostiene esta autora, desde esta perspectiva «el principio de subsidiariedad está dirigida [sic] a una división del trabajo en la protección de derechos humanos que respete el pluralismo desde una vocación de unidad de propósito y, por lo que respecta a la relación mutua entre Estados parte y TEDH ${ }^{29}$. La propuesta de Iglesias tiene la virtud de proyectar un modelo normativo de residualidad con exigencias de argumentación racional. Entendido así, no se trata de definir las cuestiones de cooperación en un plano conceptual abstracto, sino que también resulta indispensable la creación de un espacio «ecológico» para la interacción bajo cargas de argumentación en cada ocasión en la que se libera el margen. El MAN supone aquí un compromiso institucional de cooperación que tiene como finalidad preservar y desarrollar un campo común de intereses comunes y responsabilidades compartidas. De este modo, «el razonamiento del TEDH en aplicación del Convenio consiste en examinar si la medida estatal impugnada consigue alcanzar un balance equitativo entre derechos individuales y valores democráticos, atendiendo al dualismo axiológico entre democracia y derechos que imbuye el propio Convenio» ${ }^{30}$.

Un segundo argumento, al que se puede llamar argumento procesal, plantea la hipótesis de que el MAN sería una cláusula de concreción de un recurso excepcional de amparo europeo conforme al cual el TEDH se habría convertido, a los efectos prácticos, en un verdadero Tribunal Constitucional de la Unión Europea. De este modo, el MAN permitiría adoptar solo aquellas decisiones que favorezcan un mínimo de protección sobre la base de un amparo objetivo más que subjetivo, orientado, ya no tanto a la protección de singulares derechos de los ciudadanos, sino más bien a la interpretación uniformadora del convenio, buscando así las zonas de consenso. De este modo, «[e]l Tribunal hace referencia al margen de apreciación, permitiendo que en ciertos derechos en los que no exista un consenso en su aplicación cada Estado tenga la posibilidad de protegerlo conforme a sus cánones internos» ${ }^{31}$.

Existe un tercer argumento, al cual se lo podría denominar el argumento de la sensatez. García Roca lo esboza al sostener que «por sensatez [la Corte] de-

29 Marisa Iglesias Vila, «Subsidiariedad y tribunales internacionales de derechos humanos: ¿deferencia hacia los Estados o división cooperativa del trabajo?», Derecho PUCP, n. ${ }^{\circ} 79$ (2017): 209, https:/ / doi.org/10.18800/derechopucp.201702.009

30 Iglesias Vila, «Subsidiariedad y tribunales internacionales de derechos humanos», 209.

31 Sánchez-Molina, «Margen de apreciación nacional», 6, nota 10. 
bería frenar cierto ingenuo universalismo en la comprensión de los derechos humanos» ${ }^{32}$. En el fondo de este argumento subyace la tesis del pluralismo como base sociológica de la formación de cualquier sistema internacional (no solo del europeo) de protección de derechos humanos. Aquí el MAN expresa la necesidad de espacio de interacción entre comunidad internacional y comunidades locales con espacios culturales propios, cuya reivindicación resulta indispensable.

García Roca se ha referido al pluralismo territorial de los pueblos europeos que conforman una diversidad de 47 Estados y más de 800 millones de personas. En este contexto, parece, efectivamente, sensato incorporar alguna estrategia que permita a los tribunales supraestatales reconocer, precisamente, aquella diversidad:

... una jurisdicción unitaria o concentrada con un ámbito tan difuso no puede sino venir obligada a ser extremadamente prudente en el ejercicio de sus funciones y, por cautela, contener la intensidad de algunos de sus juicios sobre las actuaciones de los Estados miembros ${ }^{33}$.

La doctrina del MAN resulta, por lo demás, congruente con la construcción de un sistema multinivel de órdenes jurídicos que interactúan reservándose espacios mutuos sin que uno se imponga al otro como si se tratara de un sistema escalonado de niveles jerarquizados. De este modo, «la Constitución europea estaría compuesta por las constituciones nacionales y los Tratados europeos en un sistema constitucional bi- o multinivel»; se trata, además, de un orden anclado en la propia democracia constitucional que basa su legitimidad en un interés comunitario genuino «estableciendo un poder público para asuntos de interés común, extrayendo su legitimidad de los mismos sujetos que también están vinculados a sus políticas: los ciudadanos de la Unión» ${ }^{34}$.

Conforme se ha sostenido — siempre en el ámbito europeo-, «[1]a asunción de un modelo de pluralismo de constituciones supone asumir que no hay una instancia superior de resolución de conflictos; [n]i siquiera permite, conceptualmente, asumir una suerte de jerarquía inversa a favor de la Consti-

32 García Roca, «El margen de apreciación nacional...», 121, nota 9.

33 García Roca, «El margen de apreciación nacional...», 123.

34 Ingolf Pernice, «El constitucionalismo multinivel en la Unión Europea», Revista de Derecho Constitucional Europeo (ReDCE) 9, n. 17 (enero-junio 2012): 647, http:/ / www.ugr.es/ redce/ REDCE17pdf/17_pernice.pdf 
tución estatal» ${ }^{35}$. La relatividad de la soberanía nacional no supone, bajo ningún argumento, que una nueva soberanía supranacional se haya ungido por encima de las instancias nacionales. Solo sugiere que ha surgido un orden de competencias que debe articularse de la mejor manera posible. Y es, precisamente, esta articulación de fuentes, lo que con frecuencia lleva en el plano práctico a la construcción de un razonable margen de ajustes, a veces a favor de las instancias supraestatales, a veces a favor de las instancias nacionales.

El MAN expresa ese margen de interacción razonable en la diversidad de fuentes que se interrelacionan para hacer posible un constitucionalismo multinivel en la protección de los derechos humanos, que ya no es posible solo como parte de la estrategia de un único Estado, y que, más bien, forma parte de un modelo de Estado constitucional cooperativo ${ }^{36}$.

\section{El debate sobre el MAN en el Sistema Interamericano}

El debate interamericano sobre el MAN se desarrolla en medio de una discusión más amplia sobre la convencionalización de los sistemas jurídicos de la región $^{37}$. La legitimidad de la Corte IDH — tras la celebrada doctrina del control de convencionalidad - es hoy indiscutible en la región; al mismo tiempo, sin embargo, es en este mismo contexto donde también se han hecho notar ciertas reacciones locales que reclaman un mayor espacio en la toma de decisiones que se asumen como propias de la «soberanía» estatal, para decirlo en términos de reivindicación soberanista; pero es también la invocación de un razonable argumento que apela al pluralismo y tiene importantes consensos en el propio discurso constitucional y convencional.

De manera que la defensa de un margen de acción suele, a veces, confundirse con un discurso de resistencia a la jurisprudencia progresista de la Corte IDH. La sola invocación de cierto margen de acción a favor de los Estados despierta sospechas, especialmente en círculos académicos cercanos a la Corte

35 Rafael Bustos Gisbert, Pluralismo constitucional y diálogo jurisprudencial (México D.F.: Porrúa, 2012), 16.

36 Peter Häberle, El Estado constitucional (México D.F.: Universidad Nacional Autónoma de México, 2003), 68.

37 Para una síntesis de este proceso en el Sistema Interamericano puede verse el voto razonado del Juez Eduardo Ferrer Mac-Gregor, en calidad de juez ad hoc de la Corte IDH en el Caso Cabrera García y Montiel Flores vs. México, resuelto el 26 de noviembre de 2010. 
IDH. Faundez Ledesma, por ejemplo, refiere que, dado que «no se encuentra expresamente reconocida en la Convención Americana [...] tiene que ser vista, si no con recelo, por lo menos con mucha precaución» ${ }^{38}$. Se olvida así su origen jurisprudencial, aunque luego, matiza su inicial resistencia al sostener que:

... ese margen de apreciación no puede, en ningún caso, entenderse como una autorización para que los órganos del Estado interpreten libremente las disposiciones de la Convención, o como una autorización para interpretar la Convención de modo que tenga efectos diferentes en los distintos Estados ${ }^{39}$.

Más categórica es la consideración de Claudio Nash, quien, ratificando una afirmación del expresidente de la Corte IDH Antonio Cançado Trinidade, sostiene que «[e]n el sistema convencional y en la práctica jurisprudencial interamericana, no se ha dado espacio a la doctrina del margen de apreciación en su sentido estricto» ${ }^{40}$. Desde luego, una afirmación tan categórica parece deslegitimar conceptualmente la doctrina del MAN, en la medida en que, para este autor, se trataría de la «renuncia por parte del órgano internacional a realizar un control de los supuestos de valoración jurídica o fáctica propios del ejercicio de derechos humanos» ${ }^{41}$.

En esta línea, considera por ejemplo como un caso de «margen de apreciación» —aunque la Corte IDH no lo haya explicitado en tales términos—, algunas decisiones cuestionables de la Corte, como la emitida en el caso Lori Berenson vs. Perú. En el relato de Nash, «[e]n este caso, la ley antiterrorista a todas luces no cumplía con los estándares convencionales, pero la Corte termina no condenando al Estado por violación del artículo $2^{\circ}$, atendidas consideraciones implícitas de orden político ${ }^{42}$. De este modo, según prosigue, aun cuando se trataría de un caso extremo, «[s]e omite el control, sino que derechamente se permite una violación y se renuncia al control interamericano» ${ }^{43}$. Como puede

38 Héctor Faúndez Ledesma, El sistema interamericano de protección de los derechos humanos: aspectos institucionales y procesales, $3 .^{\mathrm{a}}$ ed. (San José: Instituto Interamericano de Derechos Humanos, 2004), 64 .

39 Faúndez Ledesma, El sistema interamericano de protección de los derechos humanos, 64.

40 Nash Rojas, «La doctrina del margen de apreciación y su nula recepción», 85, nota 3.

41 Nash Rojas, «La doctrina del margen de apreciación y su nula recepción», 89.

42 Nash Rojas, «La doctrina del margen de apreciación y su nula recepción», 91.

43 Nash Rojas, «La doctrina del margen de apreciación y su nula recepción», 91. 
apreciarse, en la visión de Nash, el MAN no solo es una doctrina peligrosa, sino también una manera de permitir que primen criterios políticos sobre los criterios jurídicos de convencionalidad. Se puede ser escéptico y tener una opinión crítica sobre la doctrina, pero, como dice el dicho popular, las cosas no desaparecen porque no nos gusten, y los juristas deberíamos desarrollar teorías suficientemente rigurosas como para no rehuir a la realidad cuando esta se pone en contra de nuestras convicciones.

Desde otra perspectiva, las consideraciones del profesor Ferrer Mac-Gregor han sido bastante más ponderadas y reflexivas en este tema. En un trabajo que data de una fecha anterior a su designación como juez de la Corte IDH, él sugería que «[1]a Corte Interamericana, por regla general, debe respetar ciertos márgenes decisorios de los Estados miembros, definidos en última instancia por los tribunales constitucionales nacionales (margen de prudencia)» ${ }^{44}$. De manera que, en materia de delimitación del contenido de los derechos, los tribunales nacionales deben tener un espacio para seguir la jurisprudencia de la Corte «en el ejercicio de sus funciones, en atención al deber que tienen de dar cuenta y justificar a la sociedad el sentido de sus sentencias» ${ }^{45}$. De este modo, concluye que "parece conveniente que la Corte Interamericana reconozca a los Estados un margen de apreciación y de valoración en esos casos, por ser quienes se encuentran legitimados para tomar ese tipo de elecciones en el plano nacional» ${ }^{46}$.

Jorge Contesse ha sugerido adoptar un modelo normativo de subsidiariedad que dé cuenta adecuada del papel que le corresponde a la propia Corte IDH y a cada Estado en la construcción de un campo común de actuación para la efectividad de los derechos en la región ${ }^{47}$. Su argumentación centra la atención en el papel poco reflexivo de la academia en torno al reparto de competencias y al valor intrínseco que conlleva la defensa de la legitimidad democrática de las decisiones de cada Estado, especialmente en contextos en los que ya no rigen sistemas autoritarios sino democracias en pleno desarro1lo. Contesse se ha mostrado crítico con la forma simplista en que muchas

44 Eduardo Ferrer Mac-Gregor y Fernando Silva García, «El control de convencionalidad de la jurisprudencia constitucional», Parlamento y Constitución. Anuario 12 (2009), 59, https:// dialnet.unirioja.es/servlet/articulo?codigo $=3286690$

45 Ferrer Mac-Gregor y Silva García, «El control de convencionalidad», 59.

46 Ferrer Mac-Gregor y Silva García, «El control de convencionalidad», 61.

47 Contesse, «Contestation and deference in the Inter-american Human Rights System», nota 4. 
veces se comprende la relación entre los Estados y el Sistema Interamericano frente a las sentencias de condena:

De alguna manera se da por sentado que la Corte Interamericana dicte decisiones contra los Estados: debido a que los Estados violan los derechos humanos y existe un mecanismo regional de reparación, las personas y los grupos deben tener una forma de buscar reparación ${ }^{48}$.

Bajar la cabeza y esperar la condena no puede seguir siendo la actitud, parece decirnos.

Haciendo un recuento de la presencia de la Corte IDH en la región, Contesse encuentra que hoy en día no solo puede hablarse de un ámbito de mayor democracia, sino también de una ampliación de los derechos cuya defensa ha sido llevada hasta la corte. En este escenario, «[1]as democracias recién establecidas, en cambio, quieren participar y de hecho toman parte en la gobernanza regional; [1]a Corte está ahora a su alcance» ${ }^{49}$. Esta mayor participación sería, además, necesaria para complementar sus propias decisiones, por lo que se ha sugerido «adoptar la subsidiariedad normativa», a efectos de "promover, como una forma menos agresiva e intervencionista, un modelo más colaboracionista para la aplicación del derecho internacional de los derechos humanos» ${ }^{50}$.

De otro lado, y frente a las voces que en el Sistema Interamericano intentan reivindicar un doble orden jurídico —en el que incluso se ha pretendido sujetar a un «orden público nacional», el cumplimiento de las decisiones de la Corte Interamericana-, Abramovich ha sostenido, comentando el caso Fontevecchia contra Argentina, que la mejor fórmula es comprender la relación de simetría y no de jerarquía entre los tribunales nacionales y el tribunal internacional ${ }^{51}$. En la medida en que «[1]os casos contenciosos complejos que se

48 Contesse, «Contestation and deference in the Inter-american Human Rights System, 127 (traducción propia).

49 Contesse, «Contestation and deference in the Inter-american Human Rights System, 133 (traducción propia).

50 Contesse, «Contestation and deference in the Inter-american Human Rights System, 144 (traducción propia).

51 Víctor Abramovich, «Comentarios sobre 'Fontevecchia', la autoridad de las sentencias de la Corte Interamericana y los principios de derecho público argentino», Pensar en Derecho 10 (2017): 9-25. http://www.derecho.uba.ar/publicaciones/pensar-en-derecho/revistas/10/ comentarios-sobre-fontevecchia-la-autoridad-de-las-sentencias-de-la-corte-interamericana-ylos-principios-de-derecho-publico-argentino.pdf 
dirimen en el sistema interamericano no suelen tener un final definitivo en ninguna instancia ${ }^{52}$, conviene, más bien, comprender que lo que existe en verdad es un espacio de colaboración para el cumplimiento de las decisiones de la Corte IDH, toda vez que, al final de cuentas, esto depende de «la implementación que realizan las instituciones nacionales y de la presión social que puedan movilizar las víctimas y las organizaciones que las apoyan ${ }^{53}$. En este sentido, se trata de un compromiso que debe compartirse si se quiere participar de la melodía de los derechos en cada uno de los Estados miembros:

La corte regional en sus sentencias le envía a los Estados una partitura, pero son las instancias nacionales y provinciales las que con sus propios instrumentos ejecutan la música. Por eso, la autoridad de la Corte Interamericana nunca es final, ni tampoco es suprema, sino que es complementada por los mecanismos nacionales ${ }^{54}$.

El debate es sin duda amplio y diverso. Gargarella, por ejemplo, ha respondido los argumentos de Contesse con algo de escepticismo. No serían razones de apertura a procesos democráticos en abstracto los que debieran justificar la apelación a algún modelo de MAN; por el contrario, él cree que la cuestión relevante debería ser la valoración de si las decisiones que serán controladas por la Corte «provienen o no acuerdos democráticos profundos o - para ser más realistas - en casos específicos donde lidiamos con acuerdos democráticos amplios y profundos». De otro modo, solo estaríamos ante la validación de «acuerdos elitistas basados en una deliberación pública limitada o ausente» ${ }^{55}$. Desde esta concepción, el caso Gelman vs. Uruguay sería un candidato ideal para la aplicación del MAN, en la medida en que Uruguay deliberó ampliamente aquella ley de amnistía.

Los argumentos de Gargarella apuntan a un modelo de MAN que no deja de ser problemático. La discrecionalidad se traslada ahora al conocimiento

52 Abramovich, «Comentarios sobre 'Fontevecchia', la autoridad de las sentencias de la Corte Interamericana, 22.

53 Abramovich, «Comentarios sobre 'Fontevecchia', la autoridad de las sentencias de la Corte Interamericana, 22.

54 Abramovich, "Comentarios sobre 'Fontevecchia', la autoridad de las sentencias de la Corte Interamericana, 22.

55 Roberto Gargarella, «Tribunales internacionales y democracia: enfoques deferentes o de interferencia», Revista Latinoamericana de Derecho Internacional, n. ${ }^{\circ} 4$ (2016). 
del canon para establecer cuándo un debate es genuinamente deliberativo. Si una ley de amnistía ampliamente discutida en distintos niveles de una sociedad democrática solo se aprueba con un margen mínimo en la Asamblea Legislativa, mientras las evidencias de las graves violaciones a los derechos humanos que se intentan conculcar con dicha ley son objetivas e irrefutables, ¿igual se debe favorecer la decisión democrática por encima de la decisión de las «élites» que actúan con base en evidencias y no en votos?

Parece que al mismo tiempo debemos confiar tanto en los procesos de deliberación democráticos como en la posibilidad de una justificación racional a la hora de evaluar el MAN, que no debe ser discrecional, sino argumentativo. Desde una concepción normativa, hay buenas razones para mirar el MAN como una estrategia de argumentación racional que permite a la Corte IDH tener presentes criterios de razonabilidad a la hora de justificar sus decisiones. Las decisiones razonables son aquellas que toman en cuenta el contexto, la pertinencia de las razones, las consecuencias y la diversidad: «[h]ay muchas cuestiones sobre las que las personas razonables pueden discrepar razonablemente ${ }^{56}$, especialmente en cuestiones complejas, que son los casos que llegan a la Corte. Y es la constatación de este hecho, aparentemente trivial y hasta obvio, lo que se coloca en la base para asumir que también los tribunales internacionales pueden encontrar «más de una respuesta razonable» ${ }^{57}$.

El MAN resulta, así, el corolario de aceptar que en todo orden jurídico los jueces deben pronunciar decisiones razonables, para lo cual cuentan siempre con un margen de apreciación de lo que resulta razonable para cada caso: «[1] o que justifica el recurso al requisito de razonabilidad — dice MacCormickes la existencia de una pluralidad de factores que requieren ser evaluados en cuanto a su pertinencia para un foco común de interés ${ }^{58}$. Ignorar estas cuestiones «pertinentes» para un caso o introducir algo como tal cuando debiera ser ignorado llevaría a tomar decisiones irrazonables, algo que le está prohibido a cualquier tribunal y, desde luego, también a un tribunal internacional.

56 Neil MacCormick, Retórica y Estado de derecho: una teoría del razonamiento jurídico (Lima: Palestra, 2016), 287.

57 MacCormick, Retórica y Estado de derecho, 287.

58 MacCormick, Retórica y Estado de derecho, 294. 


\subsection{El MAN en el contexto de actuación del Sistema Interamericano: Estados, CIDH y Corte IDH}

Vistas las cosas con un poco más de realismo, sin embargo, el MAN está presente no solo en forma explícita en las decisiones tanto de la Comisión Interamericana de Derechos Humanos (CIDH) como de la propia Corte IDH, sino que, además, ha sido motivo de reflexión académica en los últimos años, aceptando incluso la conveniencia de su presencia y desarrollo. Algunos casos primigenios muestran una tímida invocación en supuestos no contenciosos, como ocurrió en el caso de la Opinión Consultiva OC-04/84 ${ }^{59}$ relativa a la reforma sobre el acceso a la ciudadanía planteada por Costa Rica. Analizando la propuesta de reforma constitucional que establecía un trato diferenciado, la Corte sostuvo que «[s]e trata de valores que adquieren dimensiones concretas a la luz de la realidad en que están llamados a materializarse y que dejan un cierto margen de apreciación para la expresión que deben asumir en cada caso $»^{60}$.

Un reporte del año $2012^{61}$ muestra un conjunto importante de decisiones de la CIDH que, en fase de admisión, usa de modo explícito la doctrina del margen de apreciación. Su invocación aparece, en todos los casos, como argumento del Estado, ya sea apelando a un cierto «consenso interno» para rechazar las visitas íntimas de personas LGTB privadas de libertad ${ }^{62}$, para negarse a legislar sobre las técnicas de reproducción asistida ${ }^{63}$ o para justificar la prohibición de la pornografía en las revistas, apelando a la protección de los menores y la moral pública ${ }^{64}$. En otro informe, la CIDH se refiere de modo explícito al «carácter restrictivo» con que debe usarse el «margen de aprecia-

59 Propuesta de Modificación a la Constitución Política de Costa Rica Relacionada con la Naturalización, Opinión Consultiva OC-4/84, Ser. A Nº 4, ene. 19, 1984.

60 Propuesta de Modificación a la Constitución Política de Costa Rica Relacionada con la Naturalización, Opinión Consultiva OC-4/84, Ser. A No 4, ene. 19, 1984, párr. 58.

61 Manuel Núñez Poblete. Sobre la doctrina del margen de apreciación nacional: la experiencia latinoamericana confrontada y el thelos constitucional de una técnica de adjudicación del Derecho Internacional de los Derechos Humanos (México D.F.: Instituto de Investigaciones Jurídicas, 2012).

62 CIDH, Informe núm. 71/99, caso núm. 11.656, Marta Lucía Álvarez Giraldo vs. Colombia, 4 de mayo de 1999 (admisibilidad), párr. 2.

63 CIDH, Informe núm. 25/04, caso núm. 12.631, Ana Sánchez Villalobos y otros vs. Costa Rica, 11 de marzo de 2004 (admisibilidad).

64 CIDH, Informe núm. 50/05, caso núm. 369/04, Jorge Luis Cháves Cambronero vs. Costa Rica, 12 de octubre de 2005 (admisibilidad). 
ción, el cual debe ser siempre concebido tendiente al refuerzo del sistema y sus objetivos» ${ }^{65}$.

Estos informes, sin embargo, no prueban que en el sistema interamericano el MAN haya triunfado, y ni siquiera que esté cumpliendo un papel relevante. Solo dan cuenta, en todo caso, de que se trata de un argumento al que hay que recurrir cuando las afectaciones invocadas no resultan suficientemente convincentes o cuando, como ya se ha dicho, pueden ser expuestos argumentos razonables sobre la variedad de formas en las que puede ser cumplida una obligación resultante de un tratado internacional.

A nivel de la Corte, no obstante, los casos, si bien más escasos, dan cuenta con absoluta claridad no solo de su presencia como algo natural en el razonamiento convencional, sino también muestran que su uso debe ser siempre excepcional y que, en ningún caso, se ha de utilizar para convalidar las violaciones en el núcleo de los derechos garantizados por la CADH. Este es el caso de Herrera Ulloa vs. Costa Rica, referido a la configuración legal del derecho a los recursos. En esa ocasión, la Corte sostuvo que «[s]i bien los Estados tienen un margen de apreciación para regular el ejercicio de ese recurso, no pueden establecer restricciones o requisitos que infrinjan la esencia misma del derecho de recurrir del fallo», por lo que, si bien la regulación queda librada a los Estados, el control resulta irrenunciable respecto del grado de eficacia de aquellos $^{66}$.

Este ha sido también el razonamiento de la Corte IDH en su Opinión Consultiva OC-4/84, del 19 de enero de 1984, referida a una propuesta para modificar la Constitución Política de Costa Rica en relación con la naturalización. La Corte, reconociendo la presencia de un «margen de apreciación reservado al Estado que otorga la nacionalización sobre los requisitos y conclusiones que deben llenarse para obtenerla ${ }^{67}$, fue de nuevo enfática, sin embargo, al sostener que «[d]e ningún modo podría verse en ella una aprobación a la tendencia existente en algunas partes a restringir exagerada e injustificadamente el ámbito de ejercicio de los derechos políticos de los naturalizados» ${ }^{68}$. El margen de

65 CIDH, Informe núm. 30/93, caso núm. 10.804, José Efraín Montt vs. Guatemala, 12 de octubre de 1993, párr. 24.

66 Corte IDH, caso Herrera Ulloa vs. Costa Rica, sentencia del 2 de julio de 2004.

67 Corte IDH, caso Herrera Ulloa vs. Costa Rica, sentencia del 2 de julio de 2004, párr. 62.

68 Corte IDH, caso Herrera Ulloa vs. Costa Rica, sentencia del 2 de julio de 2004, párr. 62. 
nuevo aparece para reconocer un espacio de competencias ineludible a favor del Estado, pero en ningún caso para proscribir derechos.

En el muy citado caso Castañeda Gutman vs. México, la Corte IDH ha reiterado nuevamente su doctrina del margen de apreciación condicionada. Según la Corte, en materia electoral los Estados tienen un margen para regular requisitos, condiciones y también para establecer restricciones en el ejercicio de los derechos políticos:

... [s]iempre que no sean desproporcionados o irrazonables, se trata de límites que legítimamente los Estados pueden establecer para regular el ejercicio y goce de los derechos políticos y que se refieren a ciertos requisitos que las personas titulares de los derechos políticos deben cumplir para poder ejercerlos ${ }^{69}$.

En el marco de la actuación del TEDH, como hemos visto, con frecuencia, en la base para invocar el MAN se encuentra la falta de consenso entre los Estados o al interior del propio Estado respecto de algunas de las dimensiones, sobre todo si se trata de dimensiones nuevas de los derechos reconocidos. Este fue el argumento que invocó el Estado chileno en el caso Atala Riffo y niñas vs. Chile: «los Estados prestaron su consentimiento a una idea de derechos humanos que tenía en mente ciertos tipos de violación, y no otras que en su momento no existían» ${ }^{70}$, alegó Chile, a lo que la Corte respondió:

... la presunta falta de un consenso al interior de algunos países sobre el respeto pleno por los derechos de las minorías sexuales no puede ser considerado como un argumento válido para negarles o restringirles sus derechos humanos o para perpetuar y reproducir la discriminación histórica y estructural que estas minorías han sufrido ${ }^{71}$.

Podrá alegarse que en este caso la Corte IDH no está trabajando con la doctrina del MAN, pero es claro que la tiene presente y se mantiene en diálogo con su estructura argumental. La Corte responde en forma bastante más categórica a como lo ha hecho el propio TEDH, tanto a la hora de fijar sus límites, como también al momento de identificar sus fundamentos. La Corte

69 Corte IDH, caso Castañeda Gutman vs. México, sentencia de 6 de agosto de 2008 (excepciones preliminares, fondo, reparaciones y costas), párr. 155.

70 Corte IDH, caso Atala y Niñas vs. Chile, sentencia del 24 de febrero de 2012, párr. 92.

71 Corte IDH, caso Atala y Niñas vs. Chile, sentencia del 24 de febrero de 2012, párr. 92. 
perfila un MAN que reside en las competencias de cada Estado, no solo para desarrollar el contenido de los derechos y el ámbito de las restricciones, sino también —como se establecerá en el último acápite de este trabajo- para dejar claro un margen de colaboración ineludible a la hora de implementar el cumplimiento de las decisiones de la propia Corte IDH.

Un caso interesante en el que puede hablarse de una suerte de MAN para la enmienda y reparación desde el propio Estado es lo que se presenta en el caso Andrade Salmón vs. Bolivia ${ }^{72}$. Los hechos están relacionados con una serie de violaciones a la libertad personal, acceso a recursos judiciales, incluido el habeas corpus, de las que habría sido víctima la señora María Nina Lupe del Rosario Andrade Salmón; a ella se le habían imputado una serie de delitos contra los fondos públicos durante el ejercicio de cargos concejales y como alcaldesa de la ciudad de La Paz. El Estado aceptó los cargos y dispuso las medidas reparatorias pertinentes durante el curso del proceso ante la Corte IDH:

... [e]n atención a esta situación, la Corte reiteró su criterio según el cual aquellos casos en los que el Estado reconozca su responsabilidad internacional ante instancias interamericanas, haya hecho cesar el acto violatorio de los derechos de las víctimas (p. ej., a través de un adecuado control de convencionalidad que garantizó la protección de sus derechos), y haya realizado una reparación acorde con los estándares del Sistema Interamericano, se entiende que aquel no es internacionalmente responsable ${ }^{73}$.

Aun cuando el juez Ferrer Mac-Gregor ve en este caso un supuesto de «buena práctica nacional» ${ }^{74}$, en la realidad se presenta como un supuesto de

72 Corte IDH, caso Andrade Salmón vs. Bolivia, sentencia del 01 de diciembre de 2016.

73 Eduardo Ferrer Mac-Gregor, «Control de convencionalidad y buenas prácticas sobre el diálogo judicial entre la Corte Interamericana de Derechos Humanos y los tribunales nacionales», En Cumplimiento e impacto de las Sentencia de la Corte Interamericana y el Tribunal Europeo de Derechos Humanos: transformando realidades, eds. Armin von Bogdandy, Eduardo Ferrer Mac-Gregor, Mariela Morales Antoniazzi, Pablo Saavedra Alessandri, 613-640 (Querétaro: Universidad Nacional Autónoma de México, 2019), 629, https:/ / archivos.juridicas.unam.mx/www/bjv/ libros/13/6273/25a.pdf

74 El expresidente de la Corte destaca, por lo menos, cuatro supuestos de «buenas prácticas nacionales» que, si se observa con atención, también podrían tratarse de otros tantos supuestos de prácticas de MAN. Estas serían: i) han realizado una correcta interpretación y aplicación del derecho internacional de los derechos humanos, ii) han adoptado medidas adecuadas para remediar la situación que le dio origen al caso, iii) ya han resuelto la violación alegada y han dispuesto reparaciones razonables o iv) han ejercido un adecuado control de convencionalidad. Ferrer Mac-Gregor, «Control de convencionalidad y buenas prácticas...», 626 y ss. 
MAN que impide a la Corte IDH la condena al Estado, atendiendo a la actuación de este frente a las violaciones denunciadas. Se trata, desde mi punto de vista, de un MAN positivo para afirmar la complementariedad, incluso cuando las violaciones ya han sido confirmadas por la propia Corte.

\subsection{Buscando un modelo de MAN}

Vista la presencia de la doctrina del MAN en el Sistema Interamericano, conviene reflexionar sobre cuál es el modelo ideal. Esto no supone necesariamente que se pueda lograr siempre en la práctica, pero sugiere un estándar hacia dónde ir, un ideal regulativo. El desarrollo de una cláusula abierta de MAN sin ninguna guía útil que limite a la propia corte o tribunal puede generar incertidumbre y un margen de capacidad de maniobra que, a la larga, deslegitima a la Corte IDH. Como se ha señalado con acierto, «Uma margem de apreciação muito aberta poderia colocar em risco uma das razões da existência do Direito Internacional dos Direitos Humanos que é corrigir algumas deficiências da democracia» ${ }^{75}$. El MAN, necesario en cualquier sistema internacional de protección de derechos humanos, tendrá que ser capaz de articular, por un lado, un sistema de colaboración y complementariedad entre los sistemas nacional e internacional; al mismo tiempo, sin embargo, deberá ser capaz de fijar límites suficientemente sólidos como para no desnaturalizar la idea básica de un sistema internacional de protección de derechos humanos que sea capaz de imponer sanciones ante las violaciones de estos.

Podría pensarse en algunos modelos tomando como punto de referencia la reforma del recurso de amparo en Europa hacia finales de los años noventa, tras la saturación de casos y la función de los tribunales en su relación con la jurisdicción ordinaria ${ }^{76}$. Esto supondría dejar a la Corte un margen reducido

75 Jânia Maria Lopes Saldanha y Márcio Morais Brum, «A margem nacional de apreciação e sua (in)aplicação pela Corte Interamericana de Direitos Humanos em matéria de anistia: uma figura hermenêutica a serviço do pluralismo ordenado?», Anuario Mexicano de Derecho Internacional 15 (2015): 211, http://www.scielo.org.mx/scielo.php?script=sci_arttext\&pid=S1870$46542015000100006 \& \operatorname{lng}=\mathrm{es} \& \mathrm{nrm}=\mathrm{iso} \& \mathrm{tlng}=\mathrm{pt}$

76 El movimiento por reducir el acceso a los tribunales constitucionales al ámbito propio de la interpretación del derecho constitucional estimuló reformas importantes para limitar el recurso de amparo, especialmente cuando se trata del control de decisiones judiciales. Puede verse al respecto: Pablo López Pietsch, «Objetivar el recurso de amparo: las recomendaciones de la Comisión Benda y el debate español», Revista Española de Derecho Constitucional 18, n. ${ }^{\circ} 53$ (mayo-agosto 1998): 115-151, http://www.cepc.gob.es/publicaciones/revistas/ 
a las cuestiones de interpretación integradora del Convenio; y la tutela de los derechos o las cuestiones de hecho y su disputa quedaría en manos de los Estados. También las formas de reparación son diversas y, en consecuencia, la Corte quedaría en una posición expectante o de supervisión. Después de todo, no es posible gestionar una corte que sea capaz de proteger derechos si solo puede pronunciarse luego de veinte o treinta años. Resulta fundamental, entonces, pensar en un diseño de reparto de roles. Ese es precisamente - como lo ha sugerido Contesse- el papel que puede jugar el MAN en el Sistema Interamericano.

A nivel teórico, los márgenes de acción han sido desarrollados principalmente para establecer las competencias entre lo constitucionalmente ordenado o dispuesto y lo que corresponde al legislador ordinario. Se trata, de este modo, de que las constituciones de principios no terminen por arrasar por completo las competencias del legislador democrático. El margen de acción es definido por Alexy como «el conjunto integrado de las decisiones que el legislador puede adoptar» en el marco de la Constitución, en la medida en que constituyan «las alternativas que han sido confiadas a su discrecionalidad», debido a lo cual «el margen de acción puede denominarse espacio de discrecionalidad» ${ }^{77}$.

Desde esta perspectiva, se traza una distinción entre el margen de acción estructural (MAEs) y el margen de acción epistémico o cognitivo (MAEp). El primero es definido como «aquello que, en razón de los límites, la Constitución ordena y prohíbe definitivamente» ${ }^{78}$, con lo cual surgen tres distintas posibilidades de márgenes de acción estructural: (i) el margen para la fijación de fines, (ii) el margen para la elección de medios y (iii) el margen para la ponderación ${ }^{79}$. Por otro lado, el MAEp:

... no deriva de los límites de lo que la Constitución ordena y prohíbe, sino de los límites de la capacidad para reconocer lo que la Constitución, por una parte, ordena y prohíbe, y por otra, lo que no ordena ni prohíbe, es decir, lo que confía a la discrecionalidad legislativa ${ }^{80}$.

revistaselectronicas? IDR $=6 \&$ IDN $=355 \& I D A=25403$

77 Alexy, «Epílogo a la Teoría de los Derechos Fundamentales», 19 y 21, nota 17.

78 Alexy, «Epílogo a la Teoría de los Derechos Fundamentales», 19 y 21, nota 17.

79 Alexy, «Epílogo a la Teoría de los Derechos Fundamentales», 24, 25, 40, 43 y 48.

80 Alexy, «Epílogo a la Teoría de los Derechos Fundamentales», 21. 
Los MAEp aparecen «cuando son inciertos los conocimientos acerca de lo que está ordenado, prohibido o confiado a la discrecionalidad del legislador por los derechos fundamentales ${ }^{81}$, ya sea porque hay una falta de certeza en relación con las premisas empíricas o con las premisas normativas.

Con esta referencia conceptual podemos ahora regresar al ámbito de las relaciones entre la Corte IDH y las autoridades democráticas de los Estados. El establecimiento de un tribunal internacional en el marco de un convenio no puede suponer, bajo ningún término, la cesión de todo cuanto pueda disponerse desde la CADH. Es claro que un tratado compromete también a las autoridades estatales en la realización de los fines que la Convención establece. Cuando la CADH dispone en su artículo 2 que los Estados deben garantizar todos los derechos del Pacto; y si no lo estuvieran aún, «los Estados Partes se comprometen a adoptar, con arreglo a sus procedimientos constitucionales y a las disposiciones de esta Convención, las medidas legislativas o de otro carácter que fueren necesarias para hacer efectivos tales derechos y libertades», los Estados asumen un claro compromiso de actuación conjunta. Es justamente ese margen de actuación conjunta indispensable para la cooperación que inspira cualquier convenio.

Es claro que existe un margen estructural en la medida en que cada Estado tiene competencias para fijar la mejor forma de cumplimiento y garantía de los derechos. Ahora, la CADH puede ser definida también, en términos normativos, como un conjunto de principios. La teoría de los principios es no solo la que permite describir mejor la práctica de los derechos humanos en el constitucionalismo democrático, sino la que ahora hace posible identificar la necesidad de reconocimiento de márgenes epistémicos indispensables ${ }^{82}$. Dado que el conocimiento de lo que está ordenado en las cláusulas de la CADH es indeterminado en el presente y en el futuro, todas las instancias judiciales competentes para delimitar su ámbito gozan de un margen de interpretación y de adecuación de los medios a los fines que conlleva. El legislador nacional, y también las instancias nacionales, cuando se hayan pronunciado en un tema puntual, están en mejores condiciones epistémicas para la determinación del contenido final de los derechos.

81 Alexy, «Epílogo a la Teoría de los Derechos Fundamentales», 21-22, 49-50.

82 Robert Alexy. Ensayos sobre la teoría de los principios y el juicio de proporcionalidad (Lima: Palestra Editores, 2019). 
Solamente de este modo la integración regional a través de un pacto puede mantener vivo al mismo tiempo el concepto de colaboración o complementariedad en la tarea compartida de la protección de los derechos humanos que la CADH encarga a los Estados. El MAN viene a reconocer, entonces, no solo la necesidad de márgenes estructurales — que son consustanciales al reparto de competencias bajo el principio de complementariedad o residualidad-, sino también la presencia irreducible de márgenes de acción epistémicos provenientes de la indeterminación de los derechos recogidos en fórmulas de principios, una indeterminación que, por cierto, no proviene únicamente del lenguaje abstracto y ambiguo de los derechos humanos, sino, además, de su comprensión cultural diversa, que también debe ser reconocida en los procesos de concreción judicial interpretativa ${ }^{83}$.

\section{El indulto a Fujimori: un modelo dialógico de MAN}

El diálogo judicial interamericano fortalece los sistemas democráticos de la Región. La subsidiariedad y la complementariedad, como principios estructurales que arbitran la relación entre sistemas de justicia nacional y Corte Interamericana, requieren de un modelo de MAN que fortalezca la protección de los derechos humanos en la región. El control convencional del indulto al expresidente Fujimori, realizado finalmente por la Corte Suprema del Perú, muestra un interesante modelo de interacción en el que la Corte Interamericana «colabora» proponiendo argumentos de convencionalidad que luego son asumidos en sede interna, permitiendo que el control se realice desde dentro, pero en diálogo con el sistema interamericano.

\subsection{Breve resumen del caso}

Alberto Fujimori Fujimori fue elegido democráticamente como presidente de la República del Perú por primera vez en el año 1990. Sin embargo, desde el

83 Pedro Grández, «La interpretación de la Constitución como búsqueda de sentido común o la interpretación cultural de la Constitución», conferencia presentada en Diálogos constitucionales en tiempos de pandemia: la interpretación constitucional, Lima, Asociación Peruana de Derecho Constitucional (APDC), 28 de mayo de 2020. 
año 1992 implantó un gobierno autoritario con una «autocracia corrupta» ${ }^{84}$ a partir de un autogolpe de Estado mediante el cual disolvió el Congreso de la República, intervino una serie de instituciones, ordenó el arresto de varios políticos de la oposición y convocó más tarde a elecciones para a un «Congreso Constituyente Democrático» que se encargaría de elaborar una nueva Constitución, la cual fue aprobada en 1993. En septiembre del año 2000, a poco de iniciar su tercer mandato - al cual llegó a través de una serie de manipulaciones del texto constitucional- se hicieron públicos unos videos en los que se veía a su asesor principal, Vladimiro Montesinos, participando de una serie de actos de corrupción. Debido a ello, Fujimori renunció a la Presidencia de la República vía fax desde Japón.

No fue hasta el año 2007 que la justicia peruana pudo lograr el retorno de Fujimori al país, luego de que Chile aprobara un pedido de extradición (Fujimori había sido detenido en ese país en el 2005). Una vez en el Perú, Fujimori enfrentó una serie de cargos por los que fue juzgado y condenado, recibiendo en total cinco condenas ${ }^{85}$. De ellas, la que se considera más relevante es la emitida en abril del 2009 por la Sala Penal Especial en el caso conocido como Barrios Altos y La Cantuta. La investigación realizada en la jurisdicción nacional y su posterior resultado se dieron en cumplimiento de lo ordenado por la Corte

84 Conclusión 104. Comisión de la Verdad y Reconciliación, Conclusiones generales del informe final de la CVR, https:/ / www.cverdad.org.pe/ifinal/conclusiones.php

«Por lo expuesto, la CVR sostiene que en los últimos años del gobierno de Fujimori el conflicto armado interno fue manipulado con la finalidad de hacer que el régimen permaneciera en el poder. Ello sumió al país en una nueva crisis económica y en abismos de corrupción, descomposición moral, debilitamiento del tejido social e institucional, y una profunda desconfianza en la esfera pública. Todos estos rasgos constituyen, por lo menos en parte, secuelas de la forma autoritaria en que se resolvió el conflicto y configuran uno de los momentos de mayor oprobio de la historia de la República».

85 (i) Seis años de prisión por el delito de usurpación de funciones, por haber ordenado a un militar hacerse pasar por un fiscal y desaparecer los llamados «vladivideos» (condena de diciembre del 2007); (ii) veinticinco años de prisión por los delitos de asesinato y secuestro, por haber participado como autor mediato en la matanza de nueve estudiantes y un profesor de la Universidad Nacional de Educación Enrique Guzmán y Valle (La Cantuta), y quince personas en Barrios Altos, así como en el secuestro de un periodista y un empresario (condena de abril del 2009); (iii) siete años y seis meses de prisión por el delito de peculado, por haber entregado quince millones de dólares del dinero público a su exasesor Montesinos (condena del 2009); (iv) seis años de prisión por varios delitos de corrupción: espionaje telefónico, pago a medios de comunicación y compra de congresistas tránsfugas (condena del 2015); (v) ocho años de prisión por el delito de peculado doloso, por haber usado recursos públicos para financiar varios «diarios chicha» durante su campaña electoral de 1995 (condena de enero del 2015) 
IDH en las sentencias de fondo del caso Barrios Altos vs. Perú (del 14 de marzo de 2001) y del caso La Cantuta vs. Perú (del 29 de noviembre de 2006). En el primero, la Corte IDH calificó los hechos ocurridos como graves violaciones a derechos humanos; y en el segundo, como crímenes de lesa humanidad.

Ambos casos fueron llevados ante la Corte IDH debido a las Leyes de Amnistía 26479 y 26492, aprobadas por el Congreso de la República para exonerar de responsabilidad a «militares, policías, y también a civiles, que hubieran cometido, entre 1980 y 1995, violaciones a los derechos humanos o participado en esas violaciones» ${ }^{86}$, lo que impidió que se investiguen los hechos y se sancione a los responsables. En los dos casos, el Estado peruano reconoció su responsabilidad internacional ante la Corte IDH. Esta resolvió declarando que las leyes de amnistía eran incompatibles con la CADH y que el Estado peruano debía investigar y sancionar a los responsables, y cumplir el acuerdo de reparaciones suscrito con las víctimas y sus familiares. Se precisó también que las víctimas y sus familiares tenían el derecho de «conocer la verdad acerca de los hechos ocurridos» ${ }^{87}$, y que «la obligación de investigar, y en su caso enjuiciar y sancionar, adquiere particular intensidad e importancia ante la gravedad de los delitos cometidos [crímenes de lesa humanidad] y la naturaleza de los derechos lesionados» ${ }^{88}$.

En cumplimiento de lo ordenado por la Corte IDH para ambos casos, mediante sentencia del 7 de abril de 2009, Fujimori fue condenado como autor mediato por la comisión de los delitos de homicidio calificado-asesinato, bajo la circunstancia agravante de alevosía en agravio de veinticinco ciudadanos, y lesiones graves en agravio de cuatro ciudadanos (víctimas de los hechos ocurridos en Barrios Altos y La Cantuta). La Sala Penal Especial calificó los delitos mencionados como «crímenes contra la Humanidad según el Derecho Internacional Penal» ${ }^{89}$. La condena se estableció en veinticinco años de pena privativa de libertad, la cual debía cumplirse, según la Sala, hasta el 10 de febrero de 2032.

86 Corte IDH, caso Barrios Altos vs. Perú. Ficha técnica.

87 Corte IDH, caso Barrios Altos vs. Perú. Corte IDH. Sentencia de Fondo. Fundamento 47.

88 Corte IDH, caso La Cantuta vs. Perú. Corte IDH. Sentencia de Fondo. Fundamento 157.

89 Sentencia se encuentra disponible en: https://www.justiciaviva.org.pe/especiales/barriosaltos/42.pdf 


\subsection{El procedimiento del indulto}

Con estos antecedentes, pese a la advertencia de las organizaciones de derechos humanos y tras la renuncia de la ministra de Justicia, que se opuso a firmar el indulto, el 24 de diciembre de 2017 el entonces presidente de la República, Pedro Pablo Kuczynski, mediante Resolución Suprema 281-2017JUS, le otorgó a Alberto Fujimori un indulto y el derecho de gracia por razones humanitarias, respecto de las condenas y procesos penales que a dicha fecha se encontraban vigentes ${ }^{90}$. Esta decisión fue emitida en medio de una serie de denuncias que, desde semanas atrás, habían empezado a hacerse públicas en relación con la poca transparencia y legalidad del procedimiento administrativo necesario para otorgar un indulto de tal envergadura91.

Por otro lado, lo que cuestionaba aun más la legitimidad del indulto era que, semanas antes, el Congreso de la República había iniciado formalmente contra Kuczynski un trámite de vacancia presidencial por sus supuestos vínculos con la corrupción en relación con el caso Odebrecht. Tan solo cuatro días antes del indulto, el 21 de diciembre de 2017, se había votado en el Congreso la vacancia, la cual no alcanzó los votos requeridos. El hecho de que Kenyi Fujimori, hijo de Alberto Fujimori y entonces congresista de la República, así como un conjunto de congresistas allegados a él habían votado en contra de la vacancia hizo surgir dudas que apuntaban hacia una posible transacción entre Kenyi Fujimori y Kuczynski (rechazar la vacancia a cambio del indulto). Tales especulaciones se hicieron más verosímiles luego de que el 20 de marzo

90 Luis Castillo Córdova y Pedro Grández Castro (coord.), El indulto y la gracia presidencial ante el derecho constitucional y el derecho internacional de los derechos humanos: un debate en torno al indulto concedido al expresidente Alberto Fujimori (Cuadernos sobre Jurisprudencia Constitucional, 13) (Lima: Palestra Editores, 2018).

91 Entre algunos de los hechos cuestionados estaba lo siguiente: la Junta Médica Penitenciaria requerida para evaluar el estado de salud del interno estuvo conformada por un médico que ya había tratado a Fujimori con anterioridad, lo cual afectaba directamente la objetividad del informe médico; ni la Resolución Suprema 281-2017-JUS ni las actas médicas contenían una motivación suficiente sobre las razones humanitarias (enfermedad no terminal grave) que justificarían la necesidad del indulto, así como tampoco hacían referencia a las condiciones carcelarias que supuestamente generaban un grave riesgo a la vida, salud e integridad del indultado; asimismo, los documentos referidos no incluían una debida motivación sobre la razonabilidad de la decisión en relación con la gravedad de los crímenes por los que el indultado estaba cumpliendo condena; y, además, se encontraron diferencias sustanciales en el acta de la Junta Médica Penitenciaria y el «acta ampliatoria», ambas formuladas frente a una comisión de gracias presidenciales que decidió recomendar el indulto en un plazo expeditivo. 
de 2018 se publicaron unos videos en los que se veía a congresistas allegados a Kenyi Fujimori tratando de «comprar» votos para el rechazo de la vacancia $^{92}$. Pedro Pablo Kuczynski renunció al día siguiente a la Presidencia de la República.

\subsection{El indulto llega a la Corte IDH}

Antes estos sucesos políticos, el 26 de diciembre de 2017 un conjunto de organizaciones nacionales de derechos humanos y representantes de las víctimas y sus familiares, enviaron un comunicado a la Corte IDH informándole sobre el posible incumplimiento por parte del Estado peruano de lo ordenado en los casos Barrios Altos y La Cantuta vs. Perú, en relación con el deber de investigar y sancionar a los responsables de las graves violaciones de derechos humanos. Luego de solicitar información al Estado y realizar una audiencia pública, el 30 de mayo de 2018 la Corte IDH emitió una resolución de supervisión de cumplimiento en la que analizó el indulto otorgado a Fujimori.

En esta resolución, sin embargo, pese a lo que habían solicitado los representantes de las víctimas, la Corte IDH decidió no pronunciarse sobre si el indulto implicaba o no un incumplimiento por parte del Estado de su deber de investigar y sancionar; según su análisis, el control del indulto por razones humanitarias concedido a Fujimori podía ser efectuado por los órganos jurisdiccionales peruanos competentes. Si bien la defensa del Estado peruano sostuvo que los representantes de las víctimas no podían acudir a la jurisdicción de la Corte IDH por no haber agotado las vías internas, la Corte precisó que:

El requisito del previo agotamiento de los recursos de la jurisdicción interna no está contemplado en la CADH para la supervisión del cumplimiento de la Sentencia. Por tanto, en uso de sus facultades de supervisión, [la Corte] puede supervisar las actuaciones de cualquier órgano o poder del Estado que guarde relación con el cumplimiento de las reparaciones ordenadas en las Sentencias ${ }^{93}$.

92 Ver: https://elcomercio.pe/politica/audios-videos-mamani-grabaciones-discordia-clavesnoticia-510852-noticia/

93 Corte IDH, caso Barrios Altos y caso La Cantuta vs. Perú. Resolución del 30 de mayo de 2018. Supervisión de cumplimiento de sentencia obligación de investigar, juzgar y, de ser el caso, sancionar, considerando 33 . 
Al devolver el caso hacia las instancias nacionales, la Corte analizó la jurisprudencia del Tribunal Constitucional peruano relevante, citando las sentencias recaídas en los expedientes 4053-2007- PHC/TC, 03660-2010-PHC/TC y 0012-2010-PI/TC. En las dos primeras, el Tribunal Constitucional realizó un control sobre el otorgamiento de un derecho de gracia y un indulto por razones humanitarias, y declaró que «la decisión de indultar (...) es (...) irrevocable administrativamente [pero] ello no obsta que pueda ser objeto excepcionalmente de anulación en sede jurisdiccional», y que «un indulto concedido bajo un error tan grave sobre el estado de salud torna en puramente aparente la motivación en la que se sustenta el mismo» ${ }^{94}$. Asimismo, en la tercera sentencia (que se puede considerar como la decisión más relevante que la Corte IDH tomó en cuenta para «devolver» el control a la jurisdicción interna), el Tribunal Constitucional peruano trazó el siguiente estándar de razonabilidad:

... mientras de mayor peso axiológico sea el derecho fundamental violado por la conducta "perdonada", y mientras mayor desprecio por el principio-derecho de dignidad humana (artículo $1^{\circ}$ de la Constitución) haya revelado la conducta típica, mayor será la carga argumentativa de la resolución administrativa que concede el indulto o la conmutación, y además, en función de las circunstancias del caso, mayor peso deberá revestir el derecho fundamental cuya protección se pretende alcanzar con la concesión del perdón ${ }^{95}$.

Así, junto con la verificación de las vías idóneas y los recursos normativos que harían posible que el control por los órganos jurisdiccionales internos se viabilice formal y materialmente, la Corte IDH desarrolló también un conjunto de parámetros internacionales que dichos órganos debían tener en cuenta al momento de realizar el control de constitucionalidad y convencionalidad al indulto otorgado a Alberto Fujimori. Entre dichos parámetros se pueden mencionar los siguientes ${ }^{96}$ :

94 Sentencia del Tribunal Constitucional de 25 de enero de 2011, emitida en el expediente No. 03660-2010-PHC/TC respecto de José Enrique Crousillat López Torres, párr. 10 y 20. Citado por la Corte IDH en la Resolución del 30 de mayo de 2018, considerando 60.

95 Sentencia del Tribunal Constitucional de 11 de noviembre de 2011, emitida en el expediente No. 0012-2010-PI/TC, párr. 45.

96 Resolución de la Corte Interamericana de Derechos Humanos, Caso Barrios Altos y Caso La Cantuta vs. Perú. Resolución del 30 de mayo de 2018, considerandos 45, 52, 53, 55, 57. https: / / www.corteidh.or.cr/docs/supervisiones/barriosaltos_lacantuta_30_05_18.pdf 
[E]xiste una tendencia creciente en el Derecho Internacional de los Derechos Humanos y el Derecho Penal Internacional respecto a limitar que las condenas impuestas por tribunales penales por graves violaciones a los derechos humanos sean perdonadas o extinguidas por decisiones discrecionales de los Poderes Ejecutivo o Legislativo.

(...)

[Debe] analizarse si la aplicación de una figura jurídica de "indulto por razones humanitarias" constituye un obstáculo para el cumplimiento de la obligación de investigar, juzgar y, de ser el caso, sancionar tales violaciones, es preciso valorar si se produce una afectación innecesaria y desproporcionada al derecho de acceso a la justicia de las víctimas de tales violaciones y sus familiares, en cuanto a la proporcionalidad de la pena impuesta en el proceso judicial y su ejecución...

(...)

... corresponde al Estado valorar proporcionalmente cuál es la medida de carácter administrativo o figura jurídica que permita proteger la vida y la integridad del condenado, siempre que la misma se otorgue debidamente y siguiendo un fin legítimo que no signifique únicamente dejar de asegurar la ejecución de la pena.

(...)

En casos de graves violaciones de derechos humanos dicha medida o figura jurídica debe ser la que menos restrinja el derecho de acceso a la justicia de las víctimas (...) y debe ser aplicada en casos muy extremos y por una necesidad imperante.

(...)

Por tratarse de graves violaciones a los derechos humanos y tomando en cuenta el desarrollo del Derecho Penal Internacional (...), resulta necesario que, además de la situación de salud del condenado, se tomen en cuenta otros factores o criterios tales como: que se haya cumplido una parte considerable de la pena privativa de libertad y se haya pagado la reparación civil impuesta en la condena; la conducta del condenado respecto al esclarecimiento de la verdad; el reconocimiento de la gravedad de los delitos perpetrados y su rehabilitación; y los efectos que su liberación anticipada tendría a nivel social y sobre las víctimas y sus familiares.

(...)

... cuando el Presidente de la República adopta una medida discrecional que implica un perdón de la pena está afectando directamente el principio de proporcionalidad (...) que fue garantizado a través de la labor asignada a los jueces y tribunales del Poder Judicial de emitir una sentencia que individualizó, de manera motivada, la fijación de la pena, de acuerdo con la gravedad de los hechos delictivos y otros factores y circunstancias constatadas a través del proceso penal. 


\section{Ideas finales: MAN y diálogo judicial cooperativo}

Tras cerciorarse de que existen mecanismos internos para resolver el problema suscitado con el indulto, la Corte IDH deja en manos de las autoridades nacionales la respuesta al caso. El considerando 64 resume su decisión:

64. Ante la situación comprobada de que la jurisdicción constitucional podría realizar un control del "indulto por razones humanitarias" otorgado a Alberto Fujimori, en ejercicio de sus facultades de supervisión, esta Corte considera conveniente que los órganos jurisdiccionales peruanos competentes puedan pronunciarse al respecto, para efectuar un análisis que tome en cuenta los estándares expuestos en la presente Resolución y los serios cuestionamientos relativos al cumplimiento de los requisitos jurídicos estipulados en el derecho peruano. De ser necesario, este Tribunal podrá realizar un pronunciamiento posterior sobre si lo actuado a nivel interno es acorde o no a lo ordenado en la Sentencia o constituye un obstáculo para el cumplimiento de la obligación de investigar, juzgar y, de ser el caso, sancionar en los dos referidos casos por no adecuarse a los estándares indicados e impedir indebidamente la ejecución de la sanción fijada por sentencia penal (cursivas añadidas).

¿Es este un caso donde está presente la doctrina del MAN? Un concepto muy estricto del MAN dejaría seguramente fuera un caso como el presentado. Después de todo, los casos para los que se invoca la doctrina del MAN suelen ser aquellos donde la Corte decide. En este caso, la Corte parece haber decidido «no decidir». Pero el MAN, si lo vemos como una estrategia de interacción entre autoridades nacionales y sistema internacional, en su núcleo incluye una cláusula de reserva de decisión a favor de las autoridades estatales. Lo que ocurre es que, por lo general, tales decisiones ya han sido tomadas cuando la corte o el tribunal internacional se pronuncian invocando la doctrina del MAN. Podemos ahora distinguir entre un MAN convalidante y un MAN promotor.

Estamos ante un caso de MAN convalidante cuando el tribunal internacional convalida la actuación del Estado sobre la base de una razonable actuación de las instancias nacionales, o bien invocando un argumento de contexto a favor del pluralismo, o también la falta de consensos respecto de las cuestiones que constituyen materia del pronunciamiento. En cambio, los casos de MAN promotor o positivo - como también lo he denominado- son menos frecuentes y se presentan cuando la corte o tribunal internacional, en el marco del principio de subsidiariedad, abre un MAN a favor de las autoridades 
nacionales, las cuales tienen aún la posibilidad de cumplir los compromisos internacionales si es que el caso fuera devuelto.

El caso del indulto a Fujimori ante la Corte IDH muestra un ejemplo de MAN promotor o cooperativo. Se trata de un modelo de margen de apreciación nacional argumentativo que abre un diálogo cooperativo con las instancias judiciales nacionales. La Corte no solo se interesa por las vías internas, sino que hace un registro de ellas y deja claro a las instancias nacionales sobre su viabilidad. Apela al control convencional y resalta el que las instancias nacionales deben actuar conforme a los parámetros establecidos por la propia Corte IDH. Para asegurarse aun más de que es posible realizar un juicio de fondo del procedimiento del indulto, la Corte advierte que «existen serios cuestionamientos relativos al cumplimiento de los requisitos jurídicos estipulados en el derecho peruano para otorgar dicho indulto por razones humanitarias ${ }^{97}$.

Es verdad que el «margen» así delineado por la propia Corte es mínimo; a favor de este modelo débil, sin embargo, queda el hecho de que se trata de un margen justificado en cada uno de sus ámbitos: competencial, procesal y sustantivo o de fondo. La Corte tiene competencias en el marco del cumplimiento de sus sentencias; existen mecanismos procesales para que las instancias internas actúen; y, finalmente, se cuenta con evidencia sobre la interferencia irrazonable producida con la concesión del indulto.

Con estas consideraciones por parte de la Corte, una vez devuelto el caso a las autoridades peruanas, se activó un incidente en el cuadernillo de ejecución de la sentencia de condena de Alberto Fujimori a cargo del juez de Instrucción Preparatoria de la Corte Suprema de la República. En una decisión del 3 de octubre de 2018, ejerciendo el control de convencionalidad y siguiendo rigurosamente los parámetros establecidos por la Corte IDH, la Corte Suprema de la República del Perú declaró que el indulto a Fujimori violaba los compromisos del Perú con el Sistema Interamericano y dispuso la captura de Fujimori y su reingreso al recinto penitenciario. La decisión fue luego confirmada mediante decisión de la Sala Penal Especial de la Corte Suprema del 13 de febrero de $2019^{98}$.

97 Corte IDH, caso Barrios Altos y caso La Cantuta vs. Perú. Resolución del 30 de mayo de 2018, considerando 69.

98 Ladecisión confirmatoriapuedeconsultarseenlasiguientedirección:https://www.pj.gob.pe/wps/wcm/connect/2a269e00491712be9666d60375cdf40c/31.+Exp.+N.\%C2\%B0+06-2001-4+\%2813-02-2019\%29. pdf?MOD=AJPERES \&CACHEID=2a269e00491712be9666d60375cdf40c 
Aun cuando la Corte IDH no usó en ningún extremo de su pronunciamiento la expresión margen de apreciación — término que ha cuidado con recelo en los últimos tiempos-, el caso muestra un modelo de MAN que invita al diálogo judicial cooperativo. Permite un espacio de colaboración con las instancias judiciales nacionales en la construcción de un sistema efectivo de protección de los derechos humanos y, de este modo, hace posible que los ciudadanos de los Estados miembros puedan comprender mejor su papel en la justicia, ya no como un sistema escalonado de jerarquías, sino como un sistema de interacciones en el que los jueces nacionales tienen una función fundamental que cumplir.

\section{REFERENCIAS}

Abramovich, Víctor. «Comentarios sobre 'Fontevecchia', la autoridad de las sentencias de la Corte Interamericana y los principios de derecho público argentino». Pensar en Derecho 10 (2017): 9-25. http://www.derecho.uba.ar/publicaciones/pensaren-derecho/revistas/10/comentarios-sobre-fontevecchia-la-autoridad-de-lassentencias-de-la-corte-interamericana-y-los-principios-de-derecho-publicoargentino.pdf

Alexy, Robert. «Epílogo a la Teoría de los Derechos Fundamentales». Revista Española de Derecho Constitucional 22, n. ${ }^{\circ} 66$ (2002, septiembre-diciembre,) 13-64. https:// dialnet.unirioja.es/servlet/articulo?codigo $=289390$

Alexy, Robert. Ensayos sobre la teoría de los principios y el juicio de proporcionalidad, Lima: Palestra Editores, 2019.

Barbosa Delgado, Francisco R. «Los límites a la doctrina del margen nacional de apreciación en el Tribunal Europeo y la Corte Interamericana de Derechos Humanos: intervención judicial en torno a ciertos derechos de las minorías étnicas y culturales». Revista Derecho del Estado, n. 26 (2011, enero-junio): 107-135. https:/ / revistas.uexternado.edu.co/index.php/derest/article/view/2881

Bustos Gisbert, Rafael. Pluralismo constitucional y diálogo jurisprudencial. México D.F.: Porrúa, 2012. 
Castillo Córdova, Luis y Pedro Grández Castro (coord.). El indulto y la gracia presidencial ante el derecho constitucional y el derecho internacional de los derechos humanos: un debate en torno al indulto concedido al expresidente Alberto Fujimori (Cuadernos sobre Jurisprudencia Constitucional, 13). Lima: Palestra Editores, 2018.

Comisión de la Verdad y Reconciliación. Conclusiones generales del informe final de la CVR. https://www.cverdad.org.pe/ifinal/conclusiones.php

Contesse, Jorge. «Contestation and deference in the Inter-american Human Rights System». Law and Contemporary Problems 79, n. 2 (2016): 123-145. https:// scholarship.law.duke.edu/lcp/vol79/iss2/6/

Faúndez Ledesma, Héctor. El sistema interamericano de protección de los derechos humanos: aspectos institucionales y procesales. $3 .^{a}$ ed. San José: Instituto Interamericano de Derechos Humanos, 2004.

Ferrer Mac-Gregor, Eduardo. «Control de convencionalidad y buenas prácticas sobre el diálogo judicial entre la Corte Interamericana de Derechos Humanos y los tribunales nacionales». En Cumplimiento e impacto de las Sentencia de la Corte Interamericana y el Tribunal Europeo de Derechos Humanos: transformando realidades, editado por Armin von Bogdandy, Eduardo Ferrer Mac-Gregor, Mariela Morales Antoniazzi, Pablo Saavedra Alessandri, 613-640. Querétaro: Universidad Nacional Autónoma de México, 2019. https://archivos.juridicas.unam.mx/www/bjv/ libros/13/6273/25a.pdf

Ferrer Mac-Gregor, Eduardo y Fernando Silva García. «El control de convencionalidad de la jurisprudencia constitucional». Parlamento y Constitución. Anuario 12, (2009): 45-72. https:/ / dialnet.unirioja.es/servlet/articulo?codigo $=3286690$

García Roca, Javier. «La muy discrecional doctrina del margen de apreciación nacional según el Tribunal Europeo de Derechos Humanos: soberanía e integración». Teoría y Realidad Constitucional, n. ${ }^{\circ} 20$ (2007): 117-143. https://doi.org/10.5944/ trc.20.2007.6778

García Roca, Javier. El margen de apreciación nacional en la interpretación del Convenio Europeo de Derechos Humanos: soberanía e integración. Navarra, Cizur Menor: Cuadernos Cívitas, Instituto de Derecho Parlamentario, Thomson Reuters, 2010.

Gargarella, Roberto. «Tribunales internacionales y democracia: enfoques deferentes o de interferencia». Revista Latinoamericana de Derecho Internacional, n. ${ }^{\circ} 4$ (2016).

Grández, Pedro. «La interpretación de la Constitución como búsqueda de sentido común o la interpretación cultural de la Constitución». Conferencia presentada en Diálogos constitucionales en tiempos de pandemia: la interpretación constitucional. Lima, Asociación Peruana de Derecho Constitucional (APDC), 28 de mayo de 2020. 
Häberle, Peter. El Estado constitucional. México D.F.: Universidad Nacional Autónoma de México, 2003. http:/ / ru.juridicas.unam.mx:80/xmlui/handle/123456789/8990

Herrera García, Alfonso. «Reseña de: El margen de apreciación nacional en la interpretación del Convenio Europeo de Derechos Humanos: soberanía e integración de Javier García Roca». Revista Española de Derecho Constitucional 30, n. 90 (2010, septiembre-diciembre): 393-397. https://dialnet.unirioja.es/servlet/ articulo?codigo $=7619529$

Iglesias Vila, Marisa. «Subsidiariedad y tribunales internacionales de derechos humanos: ¿deferencia hacia los Estados o división cooperativa del trabajo?». Derecho PUCP , n. ${ }^{\circ} 9$ (2017): 191-222. https:/ / doi.org/10.18800/derechopucp.201702.009

López Guerra, Luis María. «El diálogo entre el Tribunal Europeo de Derechos Humanos y los tribunales españoles: coincidencias y divergencias». En Nuevas tendencias en la interpretación de los derechos fundamentales, coordinado por José Vicente Gimeno Sendra y María Teresa Regueiro García, 21-44. Madrid: Universitas, 2015.

López Pietsch, Pablo. «Objetivar el recurso de amparo: las recomendaciones de la Comisión Benda y el debate español». Revista Española de Derecho Constitucional 18, n. ${ }^{\circ}$ 53, 1998, mayo-agosto): 115-151. http://www.cepc.gob.es/publicaciones/ revistas $/$ revistaselectronicas?IDR $=6 \& I D N=355 \& I D A=25403$

MacCormick, Neil. Retórica y Estado de derecho: una teoría del razonamiento jurídico. Lima: Palestra, 2016.

Martínez Estay, José Ignacio. «Autorrestricción, deferencia y margen de apreciación: breve análisis de sus orígenes y de su desarrollo». Estudios Constitucionales 12, n. ${ }^{\circ} 1$ (2014): 365-396. https://scielo.conicyt.cl/scielo.php?script=sci_ abstract\&pid=S0718-52002014000100009\&lng=pt\&nrm=iso

Nash Rojas, Claudio. «La doctrina del margen de apreciación y su nula recepción en la jurisprudencia de la Corte Interamericana de Derechos Humanos». Anuario Colombiano de Derecho Internacional, ACDI 11, (2018): 71-100. https:/ /doi. org/10.12804/revistas.urosario.edu.co/acdi/a.6539

Neves, Marcelo. Transconstitucionalismo. Sao Paulo: Martins Fontes, 2009.

Núñez Poblete, Manuel. Sobre la doctrina del margen de apreciación nacional: la experiencia latinoamericana confrontada y el thelos constitucional de una técnica de adjudicación del Derecho Internacional de los Derechos Humanos. México D.F.: Instituto de Investigaciones Jurídicas, 2012.

Pernice, Ingolf. «El constitucionalismo multinivel en la Unión Europea». Revista de Derecho Constitucional Europeo 9, n. ${ }^{\circ} 17$ (2012, enero-junio): 639-671. http:/ / www. ugr.es/ redce/REDCE17pdf/17_pernice.pdf 
Saldanha, Jânia Maria Lopes y Márcio Morais Brum. «A margem nacional de apreciação e sua (in)aplicação pela Corte Interamericana de Direitos Humanos em matéria de anistia: uma figura hermenêutica a serviço do pluralismo ordenado?». Anuario Mexicano de Derecho Internacional 15 (2015): 195-238. http:/ /www.scielo.org.mx/ scielo.php?script=sci_arttext\&pid=S1870-46542015000100006\&lng=es\&nrm=iso\& tlng $=\mathrm{pt}$

Sánchez-Molina, Pablo. «Margen de apreciación nacional (en los sistemas de protección internacional de los derechos humanos)». Eunomía. Revista en Cultura de la Legalidad 9 (octubre 2015 - marzo 2016): 224-231. https:/ /e-revistas.uc3m.es / index.php/EUNOM/article/view/2823

\section{Sobre el autor}

Profesor ordinario de la Facultad de Derecho de la Universidad Nacional Mayor de San Marcos (UNMSM) y de la Pontificia Universidad Católica del Perú (PUCP). Profesor contratado de la Universidad ESAN. Director del Instituto Palestra de Lima, Perú. Abogado por la Universidad Nacional Mayor de San Marcos, es magíster con mención en Política Jurisdiccional por la Pontificia Universidad Católica del Perú y magíster en Argumentación Jurídica por la Universidad de Alicante. Tiene estudios concluidos de doctorado en Interpretación de los Derechos Fundamentales en la Universidad de Castilla-La Mancha. 